\title{
HMGA1 down-regulation is crucial for chromatin composition and a gene expression profile permitting myogenic differentiation
}

\author{
Jan Brocher ${ }^{1,2}$, Benjamin Vogel ${ }^{2}$, Robert Hock²*
}

\begin{abstract}
Background: High mobility group A (HMGA) proteins regulate gene transcription through architectural modulation of chromatin and the formation of multi-protein complexes on promoter/enhancer regions. Differential expression of HMGA variants has been found to be important for distinct differentiation processes and deregulated expression was linked to several disorders. Here we used mouse C2C12 myoblasts and C2C12 cells stably over-expressing HMGA1a-eGFP to study the impact of deregulated HMGA1 expression levels on cellular differentiation.

Results: We found that induction of the myogenic or osteogenic program of C2C12 cells caused an immediate down-regulation of HMGA1. In contrast to wild type C2C12 cells, an engineered cell line with stable overexpression of HMGA1a-eGFP failed to differentiate into myotubes. Immunolocalization studies demonstrated that sustained HMGA1a-eGFP expression prevented myotube formation and chromatin reorganization that normally accompanies differentiation. Western Blot analyses showed that elevated HMGA1a-eGFP levels affected chromatin composition through either down-regulation of histone $\mathrm{H} 1$ or premature expression of MeCP2. RT-PCR analyses further revealed that sustained HMGA1a expression also affected myogenic gene expression and caused either down-regulation of genes such as MyoD, myogenin, lgf1, lgf2, Igfbp1-3 or up-regulation of the transcriptional repressor Msx1. Interestingly, siRNA experiments demonstrated that knock-down of HMGA1a was required and sufficient to reactivate the myogenic program in induced HMGA1a over-expressing cells.

Conclusions: Our data demonstrate that HMGA1 down-regulation after induction is required to initiate the myogenic program in $\mathrm{C} 2 \mathrm{C} 12$ cells. Sustained HMGA1a expression after induction prevents expression of key myogenic factors. This may be due to specific gene regulation and/or global effects on chromatin. Our data further corroborate that altered HMGA1 levels influence the expression of other chromatin proteins. Thus, HMGA1 is able to establish a specific chromatin composition. This work contributes to the understanding of how differential HMGA1 expression is involved in chromatin organization during cellular differentiation processes and it may help to comprehend effects of HMGA1 over-expression occurring in malign or benign tumours.
\end{abstract}

\section{Background}

Chromatin provides a platform to regulate gene expression during several biological processes such as cellular differentiation events. Epigenetic programs involve DNA methylation patterns and/or stable modifications of histone tails [1,2]. Most if not all chromatin proteins associating with nucleosomal chromatin bind only transiently and are part of dynamic networks that

\footnotetext{
* Correspondence: rhock@biozentrum.uni-wuerzburg.de

2Biocenter, University of Wuerzburg, Am Hubland, D-97074 Wuerzburg, Germany

Full list of author information is available at the end of the article
}

regulate chromatin organization and function. High mobility group (HMG) proteins are members of these dynamic networks [3]. All members of the three HMGfamilies are considered as architectural chromatin proteins. Nevertheless, each family or even each family member play distinct roles in chromatin function $[3,4]$.

The mammalian HMGA family consists of four members. Alternative splicing of the HMGA1 transcript gives rise to three variants, HMGA1a, $1 \mathrm{~b}$, and $1 \mathrm{c}$ while HMGA2 is encoded by a separate gene. Proteins of the HMGA family are characterized by conserved DNAbinding domains, the AT-hooks, and an acidic
C Biomed Central

() 2010 Brocher et al; licensee BioMed Central Ltd. This is an Open Access article distributed under the terms of the Creative Commons Attribution License (http://creativecommons.org/licenses/by/2.0), which permits unrestricted use, distribution, and reproduction in any medium, provided the original work is properly cited. 
C-terminal tail [3]. HMGA proteins bind to AT-rich DNA which is considered to be the major reason for their concentration in heterochromatin $[3,5,6]$. HMGA proteins affect the expression of many genes through architectural remodeling of the chromatin structure and by stabilizing nucleoprotein complexes called enhanceosomes built on promoter/enhancer regions $[7,8]$. In addition, HMGA proteins are part of further chromatin complexes, as has been shown for the pre-replication complex [9] and are able to influence the structure and function of large chromatin domains $[8,10]$.

During development HMGA proteins are highly expressed in early embryos and undifferentiated cells but are absent in differentiated cells [4]. Thus, a regulated HMGA expression is important for proper cell function and differentiation. High expression levels are found in many tumors and correlate with tumor malignancy [11], are linked to deregulated oncogenes and contribute to genomic instability by inhibition of proper nucleotide excision repair [12]. Several reports indicated that HMGA proteins influence expression of genes in a cell type specific manner [4].

Loss of Hmgal or Hmga2 gene function affects specific differentiation processes [4]. Hmgal knockout mice develop type 2 diabetes due to a reduced expression of the insulin receptor [13], cardiac hypertrophy and myelo-lymphoproliferative disorders [14]. HMGA2 was shown to be crucial for cardiogenesis through regulating the gene $N k x 2.5$, a cardiogenic key transcription factor [15]. A pygmy phenotype of mice is caused by a disrupted Hmga2 gene and characterized by drastic reduction of fat tissue and a deficient spermatogenesis [16,17].

Here, we demonstrate that after induction of myogenesis in C2C12 cells down-regulation of HMGA1 proteins is an early and required step allowing the progression of the myogenic program. Sustained HMGA1a expression prevented myogenic differentiation and altered the chromatin composition through interfering with the expression of myogenic genes and other architectural chromatin proteins.

\section{Results}

\section{Down-regulation of HMGA1 proteins during cellular} differentiation

Murine C2C12 cells are committed cells that initiate muscle differentiation upon growth factor withdrawal or initiate osteogenesis upon addition of the growth factor BMP2. After induction of the myogenic program major morphological changes in $\mathrm{C} 2 \mathrm{C} 12$ cells occurred on day 1-3 (cellular elongation) and on days 6-9 (cell fusion and myotube formation). Analyses of Hmgal expression by RT-PCR and Western blots revealed an immediate down-regulation of Hmgal expression after induction of myogenic differentiation reaching low or undetectable levels on day 3 and subsequent time points during differentiation, respectively (Fig. 1A). Similarly, induction of osteogenesis by BMP2 also caused down-regulation of Hmgal mRNA with a delayed onset compared to the down-regulation during myogenesis. Interestingly, HMGA1 protein levels remained well detectable even after 4 days of osteogenic differentiation (Fig. 1B). The persistence of HMGA1 protein compared to the absence of detectable mRNA might result from different protein stabilities dependent on the cellular context during the two differentiation pathways. These data support that Hmgal expression is only prominent in undifferentiated cells but down-regulated after the initiation of differentiation upon external stimuli.

\section{Characterization of $\mathrm{C} 2 \mathrm{C} 12$ cells stably expressing HMGA1a-eGFP}

To assess whether Hmgal down-regulation is required for cell differentiation we generated $\mathrm{C} 2 \mathrm{C} 12$ cells stably over-expressing HMGA1a-eGFP (C2A1a cells). As previously shown, HMGA1a-eGFP fusion proteins behave like endogenous proteins [6]. HMGA1a-eGFP expression was constant throughout the entire time the C2A1a cells were cultured under myogenic induction conditions (Fig. 2A). Western blots revealed that the over-expression of exogenous HMGA1a-eGFP in C2A1a cells resulted in a prolonged expression of endogenous HMGA1. The latter was still detectable six days after culturing C2A1a cells in differentiation medium while HMGA1 was undetectable in $\mathrm{C} 2 \mathrm{C} 12$ wild type cells

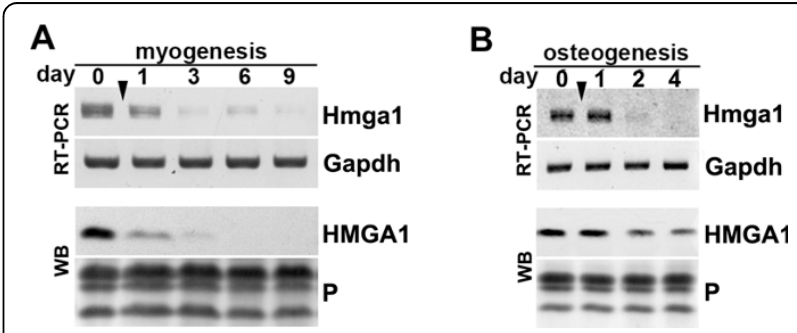

Figure 1 Differential expression of HMGA1 proteins during C2C12 cell differentiation. (A) Down-regulation of HMGA1 during myogenic differentiation of $\mathrm{C} 2 \mathrm{C} 12$ cells as analyzed by PCR and Western blotting (WB). For Western blots proteins of $1.5 \times 10^{5}$ nuclei were separated on a 15\% SDS-polyacrylamide gel. For RT-PCR $1 \mu \mathrm{g}$ of total RNA was used to produce CDNAs for the PCR reaction. For PCR identical amounts of cDNA were used. Time points of analyses are indicated in days. The arrowhead marks the time point of induction. Day 0 denotes non-induced myoblasts. Gapdh expression served as a control for the reverse transcription in RTPCR experiments. As a control for loading and Western blotting Ponceau staining (P) of core histones is shown. (B) Down-regulation of HMGA1 expression during osteogenesis. Osteogenesis in C2C12 cells was induced with $0.5 \mathrm{\mu g} / \mathrm{ml} \mathrm{BMP2}$ (arrowhead) and HMGA1 expression was analyzed at day 0 and on days 1, 3 and 4 after by RT-PCR (RT) and Western blot (WB) as described in (A). 
A

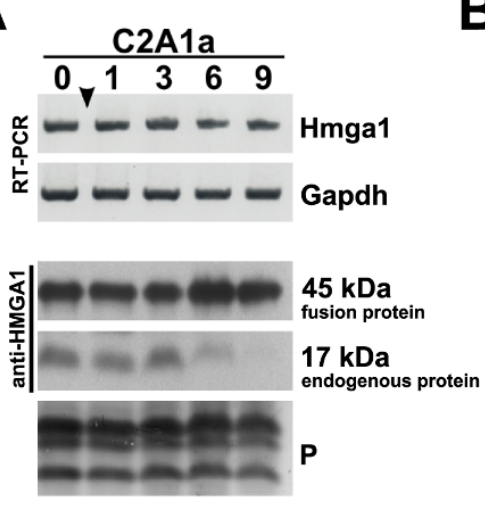

D

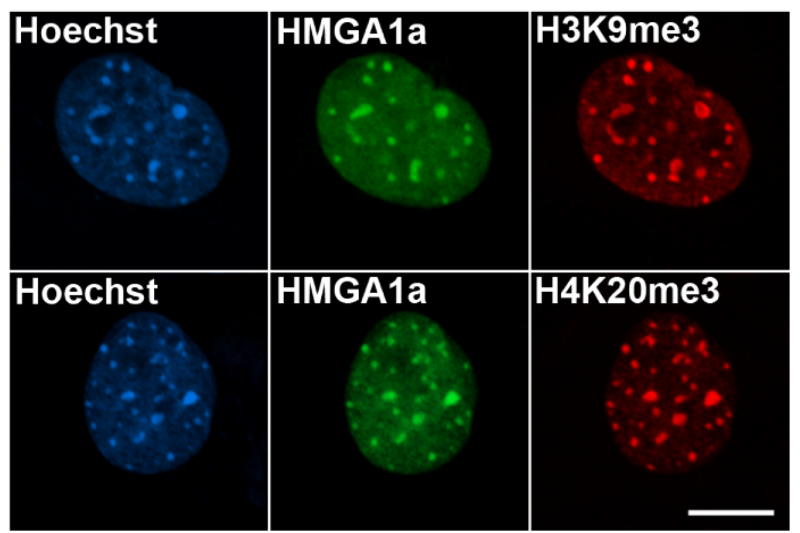

C
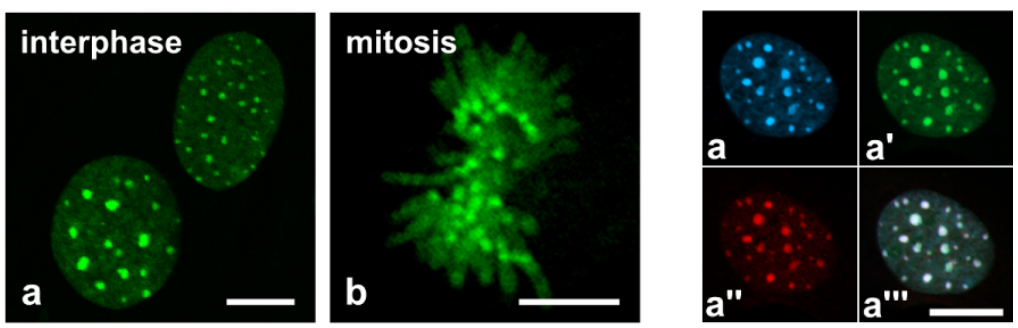

$\mathbf{E}$
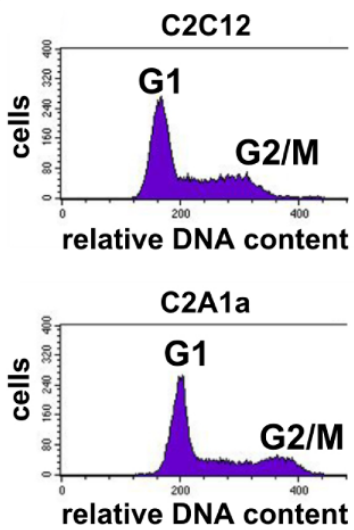

Figure 2 Characterization of the HMGA1a-eGFP over-expressing cell line C2A1a. (A) Sustained expression of HMGA1a-eGFP in C2A1a cells throughout myogenic induction analyzed by RT-PCR and Western blotting (WB) as indicated. Both, fusion protein ( 45 kDa) and endogenous protein $(\sim 17 \mathrm{kDa})$ were detected using an HMGA1-specific antibody. Note the sustained expression throughout myogenic induction. Loading controls are as mentioned in Fig. 1. (B) Localization of HMGA1a-eGFP in living C2A1a cells. Note the concentrated localization in heterochromatin foci (chromocenters) during interphase (a) and on pericentromeric regions during mitosis (b). Scale bars represent $10 \mu \mathrm{m}$. (C) Immunolocalization on fixed C2A1a cells using HP1 $\alpha$-specific antibodies. Note the colocalization of HMGA1a-eGFP (a') and HP1 $\alpha$ (a") in the chromocenters of C2A1a cells. DNA was stained with Hoechst (a). An overlay of a-a" is shown in a"'. The bar represents $10 \mu \mathrm{m}$. (D) HMGA1a-eGFP (green) colocalizes with the H3K9me3 and H4K2Ome3 specific immunolocalizations (red) in C2A1a cells. DNA was stained with Hoechst. The bar represents $10 \mu \mathrm{m}$. (E) Cell cycle phases are unaffected in the C2A1a cell line. DNA from C2C12 and C2A1a was stained with propidium iodide and 20,000 cells from each cell line were analyzed by FACS. Cell numbers (counts) are plotted against the relative DNA content of the cells. Phase distribution was analyzed with modfit Lt3.1. 56.14\% of C2C12 cells were in G1 phase, $29.54 \%$ in S phase, and $14.33 \%$ in G2 phase. In C2A1a cells $60.95 \%$ of the cells were in G1 phase, $24.43 \%$ in S phase, and $14.63 \%$ in G2 phase.

already 3 days after induction. Endogenous HMGA1 and exogenous HMGA1-eGFP were detected in parallel by an HMGA1-specific antibody to compare relative expression levels (Fig. 2A). Semi-quantitative densitometric evaluation of Western blots using ImageJ indicated a $\sim 2.6$-fold over-expression of HMGA1 proteins as compared to endogenous HMGA1 in wild type myoblasts.

In living C2A1a cells, HMGA1a-eGFP preferentially localized throughout the cell cycle in heterochromatin foci which represent pericentromeric regions fused into larger entities called chromocenters (Fig. 2B). In interphase cells it colocalized with markers for heterochromatin such as $\mathrm{HP} 1 \alpha$, histone $\mathrm{H} 3$ trimethylated at $\mathrm{K} 9$ or histone $\mathrm{H} 4$ trimethylated at $\mathrm{K} 20$ (Fig. 2C, D). In agreement with previous data that linked increased HMGA levels to enhanced cell proliferation, we counted a 2.6fold increase in the C2A1a cell number 24 hours after seeding the same amount of $\mathrm{C} 2 \mathrm{C} 12$ and $\mathrm{C} 2 \mathrm{~A} 1 \mathrm{a}$ cells. FACS analyses revealed a similar cell cycle stage distribution of the transformed and parental cells (Fig. 2E).

Stable expression of HMGA1a prevents myogenic differentiation of $\mathrm{C} 2 \mathrm{C} 12$ cells

To compare myogenesis in $\mathrm{C} 2 \mathrm{C} 12$ and $\mathrm{C} 2 \mathrm{~A} 1$ a cells we used immunolocalization experiments as well as RTPCR. Immunofluorescence indicated that C2A1a cells, but not $\mathrm{C} 2 \mathrm{C} 12$ cells, failed to fuse and to form myosin 
positive myotubes (Fig. 3A). We further tested the expression of $\alpha$-actin and myosin light chain mRNA as a marker for myogenic differentiation. In C2C12 cells, transcripts of both markers were detectable by RT-PCR shortly after induction of differentiation (Fig. 3B, left). In contrast, they were absent in $\mathrm{C} 2 \mathrm{~A} 1 \mathrm{a}$ cells grown for at least 9 days in differentiation medium (Fig. 3B, right). On the contrary, as monitored by expression of alkaline phosphatase and osteocalcin, early osteogenesis was not affected (Fig. 3C, D). Together these data demonstrate that sustained expression of HMGA1a does not interfere with early osteogenic events but specifically impairs myogenesis in $\mathrm{C} 2 \mathrm{C} 12$ cells.

\section{Sustained HMGA1a expression prevents chromocenter remodeling}

Reorganization of chromatin accompanies cellular differentiation. In $\mathrm{C} 2 \mathrm{C} 12$ cells, differentiation associated chromatin reorganization is visual as clustering of chromocenters during terminal differentiation leading to a reduced chromocenter number in differentiated cells [18]. To examine whether variations in HMGA1 levels participate in chromocenter remodeling we compared their numbers in $\mathrm{C} 2 \mathrm{C} 12$ cells, C2A1a cells (increased HMGA1 level) and C2A1a cells after HMGA1 knock-down through siRNA (reduced HMGA1 level). Successful knock-down of endogenous HMGA1 and HMGA1a-eGFP was verified by

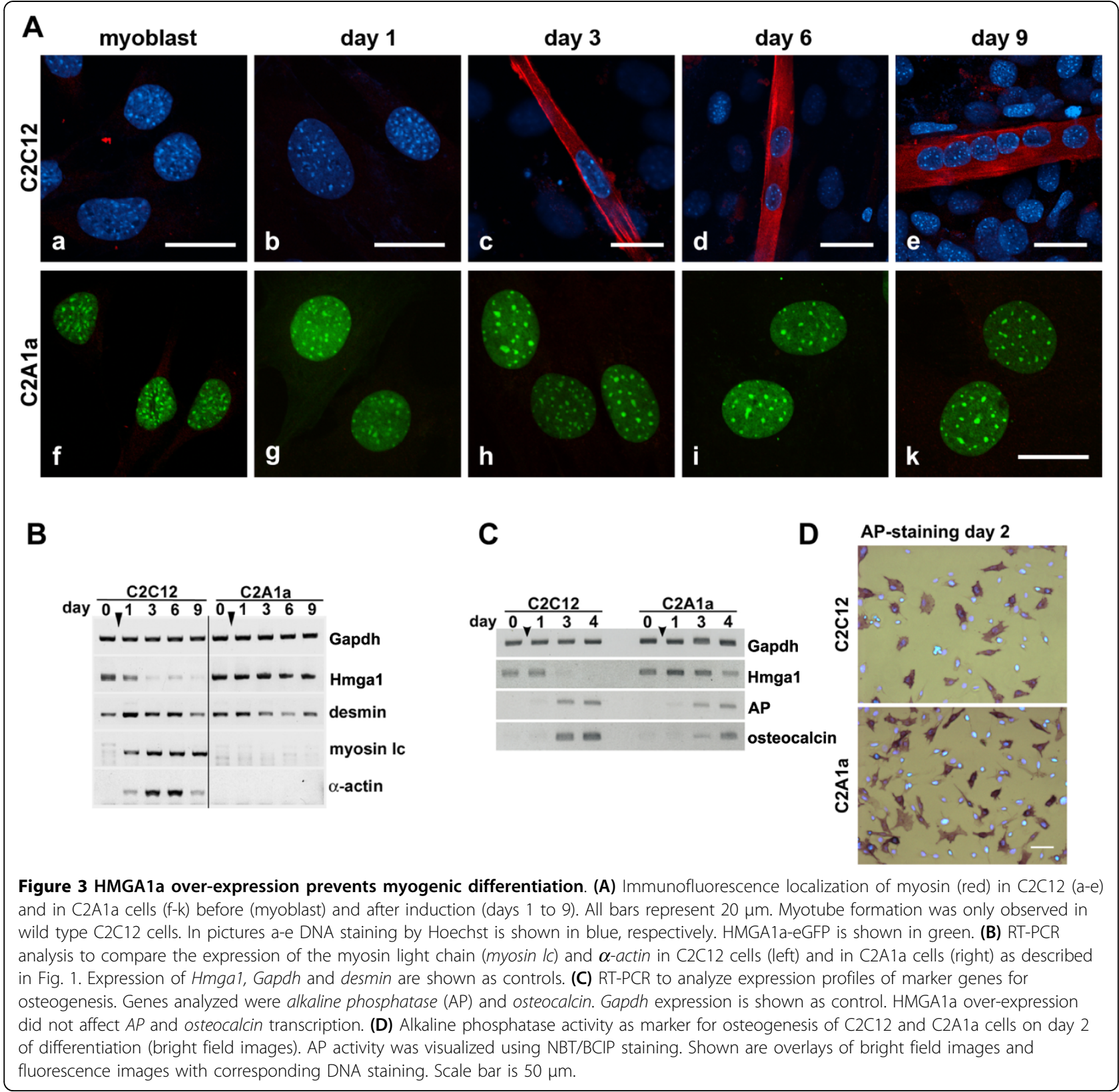


loss of eGFP-fluorescence (Fig. 4A) and by Western blot analyses (Fig. 4B). Number and distribution of chromocenters were found to be almost identical in non-induced C2C12- and C2A1a-myoblasts (Fig. 4C, a). Consistent with Brero et al., [18], reduced chromocenter numbers indicated chromocenter clustering in terminally differentiated C2C12 cells (Fig. 4C, b grey bars). In contrast, even after growing C2A1a cells for 6 days in differentiation medium, the number of chromocenters remained comparable to the number of chromocenters in noninduced cells or even shifted to an increased percentage of cells with increased chromocenter number (Fig. 4C, b). Thus, HMGA1 over-expression prevented chromocenter clustering which occurs normally through terminal differentiation and stabilized a chromocenter distribution comparable to non-induced myoblasts.

We further asked, what happens to the chromocenter organization after HMGA1a knock-down. Therefore, we
A

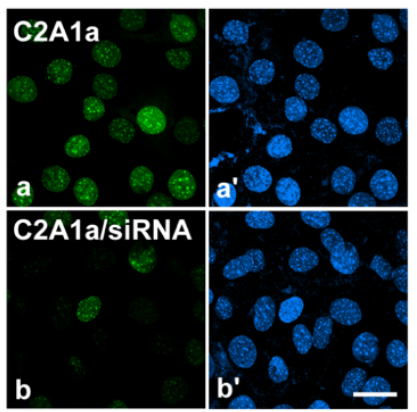

C

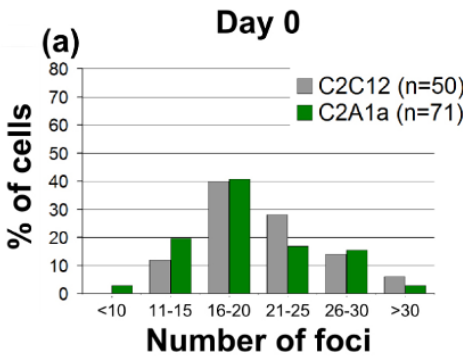

D

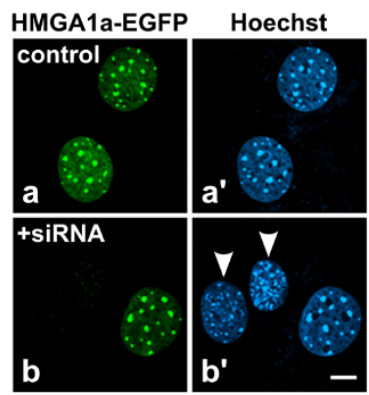

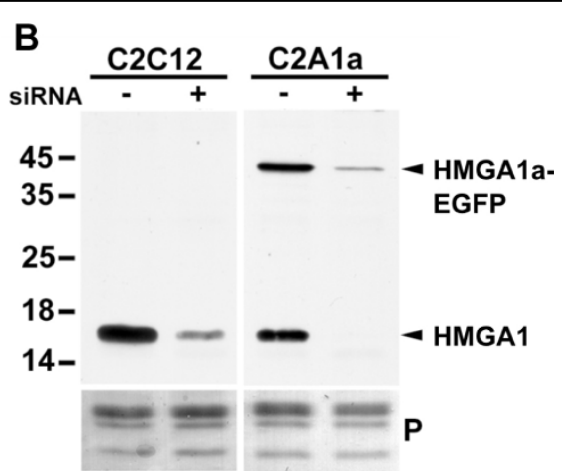

Day 6

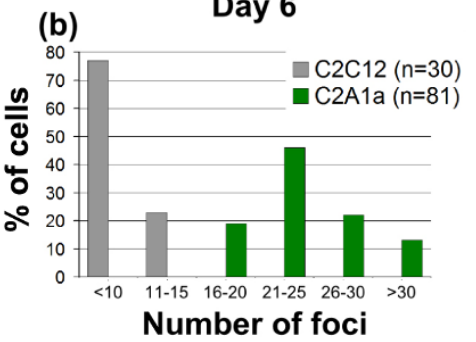

$\mathbf{E}$

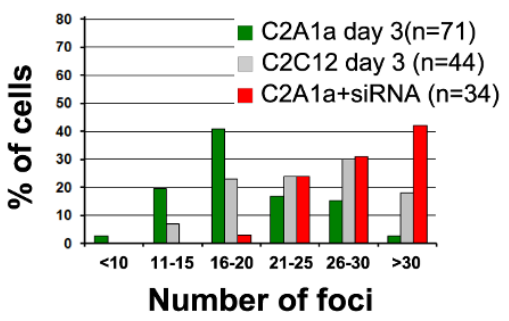

Figure 4 HMGA1a over-expression interferes with chromatin organization during myogenesis. (A) Depletion of HMGA1a-eGFP after HMGA1a-siRNA treatment is visual through the loss of eGFP fluorescence in C2A1a cells (b). Mock transfected C2A1a cells are shown in a. The corresponding Hoechst stained images are shown in a' and 'b'. The bar represents $20 \mu \mathrm{m}$. (B) Western blot analysis showed considerable depletion of endogenous and eGFP-tagged HMGA1a proteins, respectively, 12-24 hours after siRNA treatment of C2C12 and C2A1a cells. Ponceau staining $(\mathrm{P})$ of the core histones is presented as loading control. Protein molecular mass is indicated in $\mathrm{kDa}$. (C) Heterochromatin foci (chromocenters) in C2C12 and C2A1a cells were quantified ( $\mathrm{n}=$ cell number) and plotted as indicated. (a) In myoblasts (day 0 ) the number of chromocenters is identical in both cell lines. (b) During terminal muscle differentiation of the C2C12 cells, the number of heterochromatin foci decreases due to chromocenter clustering (grey columns) whereas the chromocenter number in C2A1a cells remains comparable to the number in myoblasts (green columns). (D) C2A1a control cells (a) and C2A1a cells 12-24 hours after siRNA treatment (b). HMGA1 depletion, indicated by absence of HMGA1a-eGFP, results in a higher number and a reduced size of chromocenters (arrowheads) ( $\left.b^{\prime}\right)$. The bar represents $10 \mu \mathrm{m}$. (E) Depletion of HMGA1 by siRNA in C2A1a myoblasts increased the chromocenter number (red columns) compared to C2A1a control cells (green columns). A similar chromocenter dissociation was detected in C2C12 wild type cells on differentiation day 3 (grey columns) prior to fusion during terminal differentiation. 
evaluated the chromocenter number in C2A1a myoblasts that lost their eGFP fluorescence as a marker for HMGA1 knock-down after Hoechst staining (Fig. 4D). Of note, the fraction of cell nuclei with more than 30 chromocenters significantly increased from $2.8 \%$ to $42 \%$ in cells without eGFP fluorescence $(\mathrm{p}<0.001)$. This suggests that reduced HMGA1 protein level in non-induced C2C12 cells lead to a reduced chromocenter stability. It should be noted that chromocenter dissociation was observed transiently between 12-24 hours after HMGA1 knock-down through siRNA treatment (Fig. 4E). Comparable chromocenter dissociation was observed in C2C12 cells around day 3 of differentiation when endogenous HMGA1 is down-regulated (Fig 4E, grey bars) indicating that transient chromocenter dissociation naturally and transiently occurs prior to chromocenter clustering. Together this suggests that HMGA1a overexpression stabilizes chromocenters and prevents their remodeling prior to clustering during terminal differentiation.

\section{HMGA1 over-expression alters global chromatin} composition

HMG proteins have been shown to globally affect chromatin organization and function as players in dynamic networks through regulating the access of other factors and modulators to chromatin [3]. Little is known about how HMG proteins affect chromatin composition through affecting expression of other architectural chromatin proteins. We therefore examined by Western blotting how over-expression of HMGA1a influences the expression of HMGB1, HMGN1 and histone $\mathrm{H} 1$ during cellular differentiation (Fig. 5A). The expression levels of HMGB1 and HMGN1 were different in C2C12 and C2A1a cells, displaying a slight down-regulation especially at day 1 after induction of C2A1a cells. Notably, histone $\mathrm{H} 1$ levels were constantly decreased in C2A1a cells before and throughout induction of myogenesis. In contrast, histone $\mathrm{H} 1$ levels remained unaffected after HMGA1a knock-down in uninduced C2C12 cells (Fig. 5B). This suggests that the effect on histone

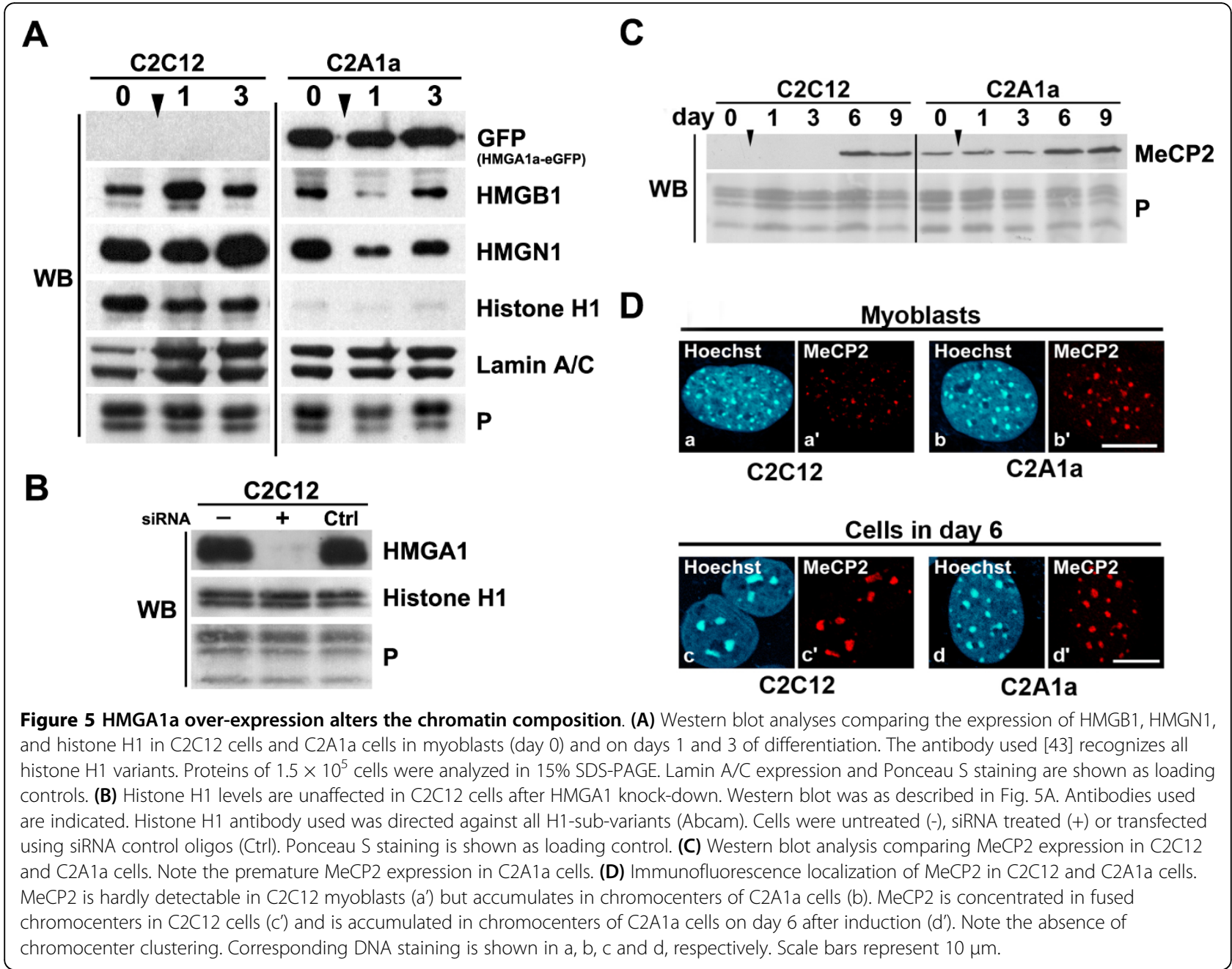


H1 expression only occurs when HMGA1a is overexpressed in C2A1a cells and that the down-regulation of histone $\mathrm{H} 1$ may be an indirect effect.

During differentiation of $\mathrm{C} 2 \mathrm{C} 12$ cells the heterochromatin associated methyl-CpG-binding protein MeCP2 is highly expressed only during terminal differentiation and involved in chromocenter clustering [18]. In contrast to HMGA1, over-expression of MeCP2 is sufficient to cause chromocenter clustering even in the absence of differentiation [18]. Therefore, we examined MeCP2 expression in more detail. Consistent with Brero et al. [18] we found that MeCP2 expression in $\mathrm{C} 2 \mathrm{C} 12$ cells started at day 6 of differentiation (Fig. 5C, left) and only a minor fraction of MeCP2 was localized in chromocenters of myoblasts (Fig. $\left.5 \mathrm{D}, \mathrm{a}^{\prime}\right)$. On day 6 of differentiation MeCP2 was concentrated in fused chromocenters in C2C12 cells (Fig.5D, c').

In contrast, we detected a premature expression of MeCP2 in C2A1a cells (Fig. 5C, right) and MeCP2 was already accumulated in chromocenters of C2A1a myoblasts (Fig. 5D, b'). Nevertheless, as mentioned earlier, chromocenter clustering was prevented in C2A1a cells (Fig. 5D, d'). Thus, HMGA1a over-expression elevates the expression of MeCP2 but also counteracts its capability to cause heterochromatin fusion.

Together, these data demonstrate that changes in HMGA1a levels cause an alteration of the expression of architectural chromatin proteins and are therefore able to modulate global chromatin composition on the level of gene expression.

\section{HMGA1a over-expression deregulates myogenic gene expression}

To examine whether the impaired myogenesis of C2A1a cells could be due to altered expression of myogenic factors we analyzed (by RT-PCR) the expression profiles of the transcription factors myogenic factor 5 and 6 (Myf5 and Myf6), myocyte enhancer factor 2A (Mef2a), the myogenic determination gene 1 (MyoD), myogenin and the myogenic inhibitor homeobox, msh-like 1 (Msx1) (Fig. 6A). Compared to $\mathrm{C} 2 \mathrm{C} 12$ cells, the expression of $M y o D$ and myogenin was significantly suppressed in C2A1a cells. Mef2a seemed to be only slightly downregulated. In contrast, the myogenic inhibitor $M s x 1$ was up-regulated. The expression profiles of other factors involved in myogenic differentiation like $M y f 5$ and $M y f 6$ (Fig. 6A) remained unaffected by sustained HMGA1a expression.

Besides transcription factors, growth factors such as insulin-like growth factor 1 and 2 (Igf1 and Igf2) are required for proper myogenesis. Igf binding proteins 1 , 2 , and 3 (Igfbp1,Igfbp2,Igfbp3) further fine tune the bioavailability of Igf1 and Igf 2 . RT-PCR analyses revealed that $I g f 1, I g f 2, I g f b p 2$ and $I g f b p 3$ were downregulated in $\mathrm{C} 2 \mathrm{~A} 1 \mathrm{a}$ cells after induction, indicating that HMGA1a that is present after induction is able to suppress the expression of components of the Igf-system (Fig. 6B).

These data illustrate that a sustained high HMGA1a protein level after induction of myogenesis alters the expression of specific genes crucial for myogenesis and prevents to establish a proper myogenic gene expression profile.

Knock-down of HMGA1 in HMGA1a over-expressing cells is sufficient to re-initiate myogenic differentiation

We performed siRNA experiments to examine whether HMGA1 knock-down would restore the ability of C2A1a cells to undergo myogenic differentiation.
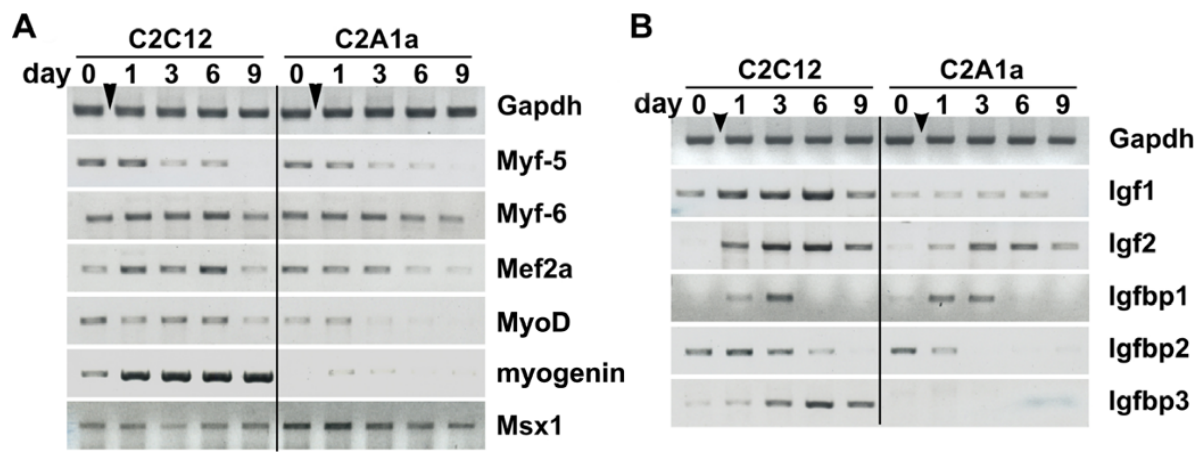

Figure 6 Sustained HMGA1a-eGFP expression interferes with the expression of myogenic genes. (A) Comparison of expression profiles of myogenic transcription factors in myoblasts (day 0) and during differentiation (days 1, 3, 6, 9 after induction). Gene expression was analyzed by RT-PCR as described in Fig. 1. Genes analyzed were: myogenic factors 5 and 6 (Myf5 and Myf6), the myocyte enhancer factor 2A (Mef2a), myogenic determination gene 1 (MyoD), myogenin and homeobox, msh-like 1 (Msx1). Note the specific down-regulation of MyoD and myogenin and the up-regulation of the myogenic inhibitor Msx1 in C2A1a cells. As loading control Gapdh expression is shown. (B) Expression profiles of components of the Igf-system in C2C12 and C2A1a cells at the time points described in (A). Genes analyzed were: insulin-like growth factors 1 and 2 (Igf1 and Igf2) and Igf binding proteins 1, 2 and 3 (Igfbp 1, Igfbp2 and Igfbp3). Note the suppression of Igf1, Igf2, Igfbp2 and Igfbp3. Gapdh expression is presented as a control. 
Notably, in C2C12 and C2A1a cells, HMGA1 knockdown through siRNA was not sufficient to initiate the myogenic program and still required induction by serum withdrawal (data not shown). However, siRNA mediated knock-down of HMGA1a in C2A1a cells was sufficient to reactivate the potential of $\mathrm{C} 2 \mathrm{~A} 1 \mathrm{a}$ cells to enter the myogenic program after induction. RT-PCR revealed regained expression of $M y o D$, myogenin, myosin $l c$ and $\alpha$-actin on day 3 after induction (Fig. 7A). these data demonstrate that down-regulation of HMGA1a is a crucial pre-requisite for the initiation of the myogenic program after induction and necessary to enable $\mathrm{C} 2 \mathrm{C} 12$ cells to establish a specific gene expression profile that is essential for the correct course of myogenic differentiation. Furthermore, knock-down of HMGA1a in C2A1a cells restored myosin expression 3-6 days after induction as well as chromocenter clustering accompanying terminal differentiation (Fig. 7B, arrows and Fig. 7C). This supports that HMGA1a down-regulation is crucial to activate the entire myogenic program including chromatin remodeling during terminal differentiation.

\section{Discussion}

HMGA1 proteins are architectural chromatin proteins known to be preferentially expressed in proliferating embryonic tissues but absent in differentiated cells $[4,19]$. HMGA1 proteins have been previously implicated in the differentiation of several cell types. For example HMGA1 affects lympho-hematopoietic differentiation of mouse embryonic stem cells [20] and the differentiation of sperm cells [21]. HMGA1 proteins bind to adipocyte-specific promoters and down-regulation has been shown to impair adipocytic differentiation of 3T3-L1 cells [22]. Here we demonstrate that HMGA1 down-regulation is one of the first and essential steps to allow myogenic differentiation of $\mathrm{C} 2 \mathrm{C} 12$ cells. In contrast, sustained expression of HMGA1a-eGFP after induction prevents myogenic differentiation. Mechanistically, the inhibition of $\mathrm{C} 2 \mathrm{C} 12$ myogenesis is caused by a specific down-regulation of the myogenic key transcription factors MyoD and myogenin and several additional factors that are required to progress myogenesis.

Several mechanisms have been described on how HMGA proteins participate in specific gene expression, for example the formation of enhanceosomes [8], binding to specific promoter regions to remove inhibitory factors and to recruit chromatin remodeling complexes or to interact with other transcription factors (e.g. Smad1/4) $[8,15,23,24]$.

The genes that are specifically targeted by HMGA1a during $\mathrm{C} 2 \mathrm{C} 12$ myogenesis remain to be examined. Certainly, the down-regulation of specific myogenic genes through HMGA1a is indirect and may represent

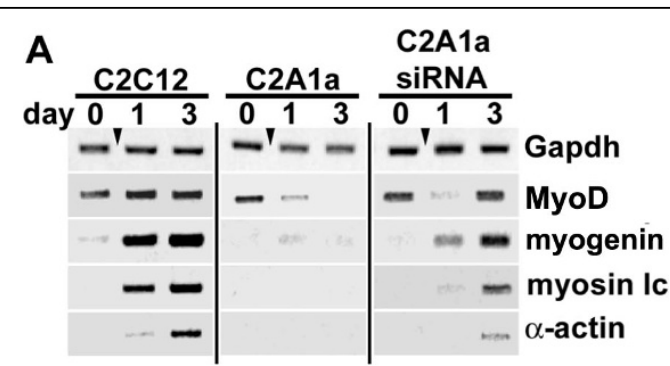

B

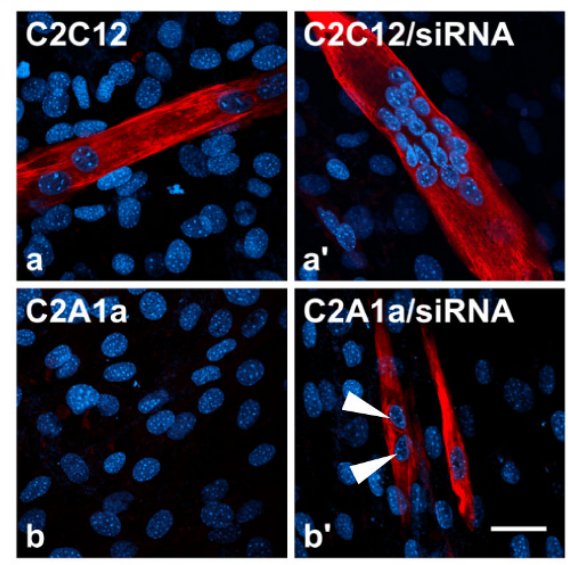

C

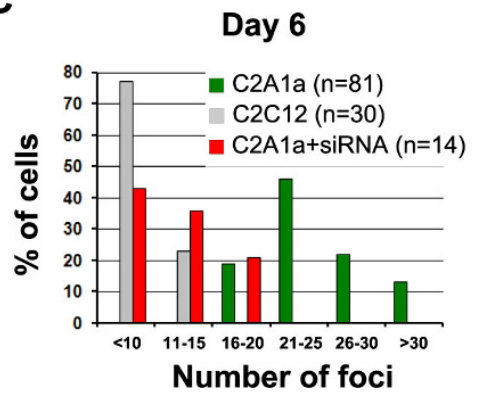

Figure 7 Recovery of myogenic gene expression in C2A1a cells after siRNA mediated HMGA1 depletion. (A) RT-PCR to analyze myogenic gene expression after HMGA1 knock-down in C2A1a cells. RT-PCR was as described in Fig. 1. Days of analyses are indicated. Gapdh expression was used as a control. Note the recovery of MyoD, myogenin, myosin $\mathrm{lc}$ and $\alpha$-actin expression on day 3 of differentiation after HMGA1 knock-down in C2A1a cells. (B) Immunofluorescence localizations of myosin (red) in C2C12 and C2A1a control cells $(a, b)$ and $C 2 \mathrm{C} 12$ and C2A1a cells treated with HMGA1 siRNA ( $\left.a^{\prime}, b^{\prime}\right)$ on day 6 after induction. DNA was stained with Hoechst (blue). The siRNA treated C2C12 cells (a') differentiate as control treated $\mathrm{C} 2 \mathrm{C} 12$ cells (a). Knock-down of HMGA1 in C2A1a cells recovers myotube formation and myosin expression ( $\left.b^{\prime}\right)$. Note that the number of chromocenters is reduced in these cells indicating chromocenter clustering (arrows). Bar represents $100 \mu \mathrm{m}$. (C) Chromocenter clustering occurs after HMGAla knock-down in C2A1a cells. Comparison of chromocenter numbers on day 6 of differentiation in terminal differentiated $\mathrm{C} 2 \mathrm{C} 12$ cells (grey columns), C2A1a on day 6 throughout induction of myogenesis (green columns) and myosin positive C2A1a cells after knock-down of HMGA1a on day 6 of differentiation (red columns). The evaluation of chromocenter numbers was as described in Fig. 4C. 
downstream effects in myogenic gene activation cascades. For example, the decreased myogenin expression is likely caused by the down-regulation of $M y o D$ as well as $M e f 2 a$. The latter was recently shown to be necessary for efficient expression of myogenin through the binding to its promoter [25]. MyoD in turn might be repressed through up-regulation of its suppressor $M s x 1$. Even though elevated $M s x 1$ expression in C2A1a cells was just prominent until three days after induction, this initial up-regulation might be sufficient to aggravate the effects of inhibition on the myogenic program. In contrast, it is also conceivable that the differential expression of these genes observed in C2A1a cells is regulated by HMGA1 independently of each other, while affecting the differentiation program in a synergistic manner. Due to this possibility, the promoters of $M y o D$, myogenin as well as $M s x 1$ are good potential candidates for being direct HMGA1a targets. Other direct candidate genes are those of the Igf-pathway which we found to be suppressed through sustained HMGA1a expression (e.g. Igf1, Igf2). Several previous reports discussed that Igfsignaling is involved in sugar metabolism [26] and myogenic differentiation [27-29] and Igf1 depletion impairs functional muscle development in mice [30-32]. Supporting that, Igf1 induces myogenin expression followed by cell cycle arrest and myogenic differentiation [33]. Depletion of Igf2 in C2 cells inhibits $M y o D$ expression and abolishes the ability of the cells to express myogenin and myosin genes [34]. Thus, the observed deregulation of the Igf-signaling through HMGA1a over-expression may cause and/or amplify the lack of key myogenic transcription factors and is in good correlation to our observed inhibition of myogenesis.

Despite specific effects on gene promoters, sustained HMGA1a expression may also affect gene regulation through a more global regulation of chromatin architecture. For example, it has been shown that HMGA1 binds to A/T-rich scaffold attachment regions (SARs) which are thought to organize larger chromatin domains [10]. Previous reports showed that HMGA proteins are preferentially associated with heterochromatin [6,35]. This is supported by the preferential localization of HMGA1a in chromocenters of $\mathrm{C} 2 \mathrm{C} 12$ cells.

HMG proteins, histone $\mathrm{H} 1$ and many other chromatin proteins are members of a large network of chromatin binding factors that dynamically modulate chromatin architecture through interaction and competition [3]. The function of this network also depends on the availability of HMGA1-interactors and competitors such as histone $\mathrm{H} 1$ [3]. HMGA1 proteins were found to induce transcription of previously suppressed plasmid templates by displacement of histone H1 from SAR elements [36]. In support, it was shown that HMG proteins in general compete for chromatin binding with histone $\mathrm{H} 1$ in living cells [37]. The significantly decreased levels of histone $\mathrm{H} 1$ in HMGA1a over-expressing C2C12 cells demonstrate a shift in the regulatory equilibrium of those two chromatin proteins, favoring HMGA1 binding to previously $\mathrm{H} 1$-suppressed sites. This could lead to the modulation of the structure and activity of large chromatin loops and thus affect myogenic gene expression.

The massive down-regulation of histone $\mathrm{H} 1$ was surprising. This raises the question how the cells could tolerate this. However, besides histone $\mathrm{H} 1$ additional chromatin proteins such as HMGB1, HMGN1 and MeCP2 were also misregulated. This indicates that the entire chromatin composition is altered and that the loss of histone $\mathrm{H} 1$ may be compensated by other chromatin proteins like HMGB1 [38] or other differentiation specific histone $\mathrm{H} 1$ variants which are not detected by the $\mathrm{H} 1$ antibodies used. Within this context it is important that the over-expression of HMGA1a-eGFP prevented chromocenter remodeling and thus global chromatin reorganization normally accompanying differentiation. Interestingly, remodeling of chromocenters was completely recovered after knock-down of HMGA1a in C2A1a cells which was visual through regained chromocenter clustering during the restored terminal differentiation. Notably, the protein MeCP2, which stabilizes chromocenter organization in differentiated cells, was up-regulated in C2A1a cells. MeCP2 dynamically interplays with HP1 proteins, and it was suggested that this interaction in turn stabilizes chromatin organization [39]. Consistently, premature MeCP2 expression in HMGA1a over-expressing C2A1a cells could therefore increase and stabilize the HP1 concentration on chromatin which in turn could stabilize a chromatin structure that prevents expression of genes relevant for myogenic differentiation.

\section{Conclusions}

We have shown that down-regulation of HMGA1 chromatin proteins is crucial to initiate the myogenic program after induction of $\mathrm{C} 2 \mathrm{C} 12$ differentiation. Thus, we provide an example how differential expression of HMGA1 proteins is involved in differentiation processes. After induction, sustained HMGA1a expression alters the transcription of genes that are relevant for initiation and the proper course of myogenic differentiation. Both, specific gene regulation and global effects on chromatin may contribute to this deregulated gene expression. Global effects involve deregulated expression of other chromatin proteins such as histone $\mathrm{H} 1$ and $\mathrm{MeCP} 2$, leading to a modified chromatin composition. More generally, these latter data propose that altered levels of HMGA1 proteins are connected to the expression of architectural chromatin 
proteins and thus are able to establish a specific chromatin composition.

This report contributes to the understanding of how the differential expression of HMGA1 proteins is involved in chromatin organization in undifferentiated cells and during differentiation processes. Furthermore, it may help to comprehend possible mechanisms of HMGA function in malign and benign tumours that over-express HMGA proteins.

\section{Methods}

\section{Cell culture and differentiation}

$\mathrm{C} 2 \mathrm{C} 12$ cells were cultured in growth medium containing DMEM $4.5 \mathrm{~g} / \mathrm{L}$ glucose (Gibco/Invitrogen), supplemented with 100 units $/ \mathrm{ml}$ Penicillin, $100 \mu \mathrm{g} / \mathrm{ml}$ Streptomycin, $2 \mathrm{mM} \mathrm{L-glutamine}$ and 10\% FCS. Myogenic differentiation was induced with differentiation medium (DM) containing DMEM $4.5 \mathrm{~g} / \mathrm{L}$ glucose, 100 units $/ \mathrm{ml}$ Penicillin, $100 \mu \mathrm{g} / \mathrm{ml}$ Streptomycin, $2 \mathrm{mM} \mathrm{L-glutamine} \mathrm{and} 2 \%$ horse serum (Gibco/Invitrogen). Osteoblast differentiation was initiated by addition of $0.5 \mu \mathrm{g} / \mathrm{ml} \mathrm{BMP2}$. C2C12 cells stably expressing HMGA1a-eGFP constructs were generated by retroviral transduction as shown below. After isolation, cell clones were grown and differentiated as described above.

293T cells were grown in DMEM $1 \mathrm{~g} / \mathrm{L}$ glucose, supplemented with 100 units $/ \mathrm{ml}$ Penicillin, $100 \mu \mathrm{g} / \mathrm{ml}$ Streptomycin and 10\% FCS.

\section{Cell transfections and production of ecotropic viruses for transduction of $\mathrm{C} 2 \mathrm{C} 12$ cells}

To produce $\mathrm{C} 2 \mathrm{C} 12$ cells stably expressing HMGA1aeGFP, cells were infected with ecotropic retroviruses. To achieve this, $293 \mathrm{~T}$ cells were transfected transiently with pHIT60 [40] including gag-pol, pcziMEE bearing the sequence of a mouse specific envelope protein (env) and pLTR-HMGA1a-eGFP. The last two plasmids were derived from pLTR-eGFP via deletion of the eGFP sequence and insertion of HMGA1a-eGFP. 293T triple transfection of retroviral vectors was performed with MATra (IBA) using $6 \mu \mathrm{g}$ of total plasmid DNA (2 $\mu \mathrm{g}$ each plasmid). Medium was changed $24 \mathrm{~h}$ after transfection and $10 \mathrm{mM}$ Na-butyrate (Sigma) was added. $8 \mathrm{~h}$ after Na-butyrate treatment cells were washed and grown for further $24 \mathrm{~h}$ in normal growth medium. Supernatant was sterile filtered $(45 \mu \mathrm{m})$ and mixed with polyprene (Sigma) to a final concentration of $8 \mu \mathrm{g} / \mathrm{ml}$. The mixture was added to the $\mathrm{C} 2 \mathrm{C} 12$ cells. After $8 \mathrm{~h}$, $\mathrm{C} 2 \mathrm{C} 12$ cells were washed once in PBS and grown for $12 \mathrm{~h}$ in growth medium. Positive colonies were manually selected using fluorescence microscopy.

\section{Alkaline phosphatase staining}

Cells grown on cover slips were fixed for $15 \mathrm{~min}$ in $2 \%$ formaldehyde/PBS. After fixation the cells were washed
2 times in ALP buffer (100 mM Tris, $\mathrm{pH} 9.5 ; 100 \mathrm{mM}$ $\mathrm{NaCl} ; 50 \mathrm{mM} \mathrm{MgCl} 2$ ) and incubated with $30 \mu \mathrm{l}$ of ALP buffer containing $4.5 \mu \mathrm{l} \mathrm{NBT}(100 \mathrm{mg} / \mathrm{ml}$ in $70 \%$ dimethylformamide; Roche) and $3.5 \mu \mathrm{l}$ BCIP $(50 \mathrm{mg} / \mathrm{ml}$ in dimethylformamide; Roche) until AP staining was visualized ( 5-10 min). After two additional washing steps, coverslips were mounted in Mowiol as described [41].

\section{FACS analysis}

$\mathrm{C} 2 \mathrm{C} 12$ and $\mathrm{C} 2 \mathrm{~A} 1 \mathrm{a}$ cells were grown in a $60 \mathrm{~mm}$ culture dish to $\sim 80-90 \%$ confluence. Cells were removed from the culture dish, washed in PBS for $10 \mathrm{~min}$ and pelleted by centrifugation. The washing step was repeated twice with a pre-warmed $2 \%$ FCS/PBS solution. Finally, cells were resuspended in $1 \mathrm{ml} 2 \% \mathrm{FCS} / \mathrm{PBS}$. Then $3 \mathrm{ml}$ ice cold ethanol was added dropwise. Cells were fixed for 1 $\mathrm{h}$ at $4^{\circ} \mathrm{C}$, washed twice in PBS and resuspended in $1 \mathrm{ml}$ PBS. $50 \mu \mathrm{g}$ of propidium iodide and $200 \mu \mathrm{g}$ of RNAse (Sigma) were added and incubated for $30 \mathrm{~min}$ at $37^{\circ} \mathrm{C}$. FACS analyses were carried out using a BD FACScan cell sorter and CellQuest Pro Software.

\section{siRNA treatment}

RNA oligos (Biomers) used for siRNA experiments were designed on basis of the genebank number AF285780: mHMGA1a-Ex5-sense, 5'-aagucaccacagcuccaggga-3'; mHMGA1a-Ex5-antisense 5'-ucccuggagcuguggugacuu3'; mA1a-Ex5-2-sense, 5'- aaggggcagacccaagaaacu-3'; mA1a-Ex5-2 antisense, 5'-aguuucuugggucugccccuu-3'. For siRNA controls the sequence of non-targeting siRNA was used as described [42]. For annealing $30 \mu \mathrm{l}$ of sense and appropriate antisense oligo $(50 \mu \mathrm{M}$ each) were mixed and $15 \mu \mathrm{l}$ of $5 \mathrm{x}$ annealing buffer $(50 \mathrm{mM}$ Tris/ $\mathrm{HCl}, \mathrm{pH} 7.5 ; 100 \mathrm{mM} \mathrm{NaCl}$ ) was added. The final concentration of the duplex was $20 \mu \mathrm{M}$. Annealing was performed in a PCR cycler at $95^{\circ} \mathrm{C}$ for 2 min and cooling down to $20^{\circ} \mathrm{C}$ over $60 \mathrm{~min}$. For siRNA transfection $2.5 \mu \mathrm{l}(50 \mu \mathrm{M})$ of each siRNA duplex were mixed and transfected into $\mathrm{C} 2 \mathrm{C} 12$ cells using TransFectin (BioRad). Knock-down of HMGA1a proteins was analyzed in nuclei isolated 12-24 hours after siRNA transfection by Western blot or by loss of HMGA1a-eGFP fluorescence.

\section{Immunofluorescence procedures}

C2C12 cell lines grown on coverslips were washed in PBS for 5 min, fixed in 2\% formaldehyde/PBS for 15 min, washed again and permeabilized for $15 \mathrm{~min}$ in $0.1 \%$ Triton X-100/PBS. After additional washing steps, cells were incubated in $100 \mathrm{mM}$ glycin/PBS. All antibody incubations were performed in a humidified chamber. Following antibodies were used for immunofluorescence: anti-MeCP2 (1:1000, abcam), antiH3K9me3 (1:1000, abcam), anti-H3K20me3 (1:500, 
abcam), anti-myosin (1:500, Sigma), anti-HP1á (1:100, Chemicon). Primary antibodies were incubated over night at $4^{\circ} \mathrm{C}$. After two washing steps in PBS, $25 \mu \mathrm{l}$ of appropriate secondary antibodies were incubated for $20 \mathrm{~min}$. To stain DNA, $10 \mu \mathrm{l}$ of Hoechst/PBS $(5 \mu \mathrm{g} / \mathrm{ml})$ were added and incubated for further 10 min. After two final washing steps, coverslips were mounted in Mowiol as described. Confocal analyses were performed with a Leica TCS-SP2/AOBS using a HCX Pl APO 63x 1.4 oil immersion objective, using sequential scans and lasers with the appropriate wavelengths.

\section{RT-PCR, PCR and cloning}

Total RNA was isolated using TriFast (Peqlab) according to the manufacturer's instruction. To produce cDNAs 1 $\mu \mathrm{g}$ of total RNA was reverse transcribed using oligo-dT18 primer and M-MLV reverse transcriptase (Promega). The cDNAs were used as template to amplify coding sequences or sequence parts of marker transcripts. The amplified fragments were analyzed on $1 \%$ agarose gels. The cDNAs coding for HMGA1a were produced by PCR using Phusion polymerase (NEB). Primers and PCR conditions can be delivered upon request to $\mathrm{RH}$. All cDNAs were subcloned and verified by sequencing.

\section{Western blots}

Cell nuclei were prepared as described [41]. $1.5 \times 10^{5}$ nuclei were loaded per lane and their proteins were separated on a 15\% SDS-polyacrylamide gel. Unstained Protein Molecular Weight Marker (Fermentas) was used as a protein size standard. SDS-PAGE and transfer onto nitrocellulose was performed as described previously [41]. Loading and transfer efficiency was controlled by Ponceau S staining and appropriate Western blot controls. Blocking was carried out with $5 \%$ non-fat dry milk in TBST for $1 \mathrm{~h}$. Nitrocellulose was washed three times in TBST for $10 \mathrm{~min}$ and incubated with the first antibody over night at $4^{\circ} \mathrm{C}$. After three washing steps in TBST nitrocellulose membrane was incubated with the appropriate peroxidase conjugated secondary antibody in blocking solution. If necessary, nitrocellulose membrane was blocked for a second time in 5\% non-fat dry milk/TBST prior to addition of the secondary antibody. Detection was performed by enhanced chemiluminescence as described [41]. Following antibodies were used for Western blot: anti-HMGA1 (1:2500, abcam), antiGFP (1:1000, Roche), anti-MeCP2 (1:2000, Upstate), anti-HMGB1 (1:1000, Michael Bustin), anti-HMGN1 (1:1000, Micheal Bustin), anti-H1 (1:1000, Abcam), antiH1 (1:500, Michael Bustin [43]) which was elicited against pure $\mathrm{H} 1$ subtractions and affinity purified against a mixture of all $\mathrm{H} 1$ sub-variants and anti Lamin $\mathrm{A} / \mathrm{C}$ (1:5000, Santa Cruz).

\section{Acknowledgements}

We thank Tzutzuy Ramirez and Ricardo Benavente for critical reading and comments on the manuscript. We further thank Thomas Fischer for assistance with the FACS analysis. We are indepted to Michael Bustin for several antibodies. This work was supported by DFG Grants to JB (GK639), BV and $\mathrm{RH}(\mathrm{Ho1804/5)}$.

\section{Author details}

${ }^{1}$ Department of Biological Sciences, National University of Singapore, 14 Science Drive 4, Block S1A, Level 6, 117543, Singapore. ${ }^{2}$ Biocenter, University of Wuerzburg, Am Hubland, D-97074 Wuerzburg, Germany.

\section{Authors' contributions}

JB engineered and characterized the C2A1a cell line, carried out a substantial part of the analysis, interpretation of the data and helped to draft the manuscript. BV performed Western blots and helped to draft the manuscript. $\mathrm{RH}$ conceived of the study, designed the experiments, participated in data acquisition and drafted the manuscript. All authors read and approved the final manuscript.

Received: 17 February 2010 Accepted: 11 August 2010 Published: 11 August 2010

\section{References}

1. Delaval K, Feil R: Epigenetic regulation of mammalian genomic imprinting. Curr Opin Genet Dev 2004, 14:188-195.

2. Trojer $P$, Reinberg D: Histone lysine demethylases and their impact on epigenetics. Cell 2006, 125:213-217.

3. Catez F, Hock R: Binding and interplay of HMG proteins on chromatin: Lessons from live cell imaging. Biochim Biophys acta 2010, 1799:15-27.

4. Hock R, Furusawa T, Ueda T, Bustin M: HMG chromosomal proteins in development and disease. Trends Cell Biol 2007, 17:72-79.

5. Reeves $\mathrm{R}$, Beckerbauer $\mathrm{L}$ : $\mathrm{HMGI} / Y$ proteins: flexible regulators of transcription and chromatin structure. Biochim Biophys Acta 2001, 1519:13-29.

6. Harrer $M$, Lührs $H$, Bustin $M$, Scheer $U$, Hock R: Dynamic interaction of HMGA1a proteins with chromatin. J Cell Sci 2004, 117:3459-3471.

7. Bianchi ME, Agresti A: HMG proteins: dynamic players in gene regulation and differentiation. Curr Opin Genet Dev 2005, 15:496-506.

8. Reeves R: Nuclear functions of the HMG proteins. Biochim Biophys Acta 2010, 1799:3-14

9. Thomae AW, Pich D, Brocher J, Spindler M, Berens C, Hock R, Hammerschmidt W, Schepers A: Interaction between HMGA1a and the origin recognition complex creates site-specific replication origins. Proc Natl Acad Sci USA 2008, 105:1692-1697.

10. Saitoh Y, Laemmli UK: Metaphase chromosome structure: bands arise from a differential folding path of the highly AT-rich scaffold. Cell 1994, 76:609-622.

11. Sgarra R, Rustighi A, Tessari MA, Di Bernardo J, Altamura S, Fusco A, Manfioletti G, Giancotti V: Nuclear phosphoproteins HMGA and their relationship with chromatin structure and cancer. FEBS Lett 2004, 574:1-8.

12. Adair JE, Kwon Y, Dement GA, Smerdon MJ, Reeves R: Inhibition of nucleotide excision repair by high mobility group protein HMGA1. J Biol Chem 2005, 280:32184-32192.

13. Foti $D$, Chiefari $E$, Fedele $M$, luliano R, Brunetti $L$, Paonessa F, Manfioletti G, Barbetti F, Brunetti A, Croce CM, Fusco A, Brunetti A: Lack of the architectural factor HMGA1 causes insulin resistance and diabetes in humans and mice. Nat Med 2005, 11:765-773.

14. Fedele M, Fidanza V, Battista S, Pentimalli F, Klein-Szanto AJP, Visone R, De Martino I, Curcio A, Morisco C, Del Vecchio L, Baldassarre G, Arra C, Viglietto $G$, Indolfi C, Croce CM, Fusco A: Haploinsufficiency of the Hmga1 gene causes cardiac hypertrophy and myelo-lymphoproliferative disorders in mice. Cancer Res 2006, 66:2536-2543.

15. Monzen $K$, Ito $Y$, Naito AT, Kasai H, Hayashi D, Shiojima I, Yamazaki T, Miyazono K, Asashima M, Nagai R, Komuro I: A crucial role of a high mobility group protein HMGA2 in cardiogenesis. Nat Cell Biol 2008, 10:567-574.

16. Zhou X, Benson KF, Ashar HR, Chada K: Mutation responsible for the mouse pygmy phenotype in the developmentally regulated factor HMGI-C. Nature 1995, 376:771-774. 
17. Chieffi P, Battista S, Barchi M, Di Agostino S, Pierantoni GM, Fedele M, Chiariotti L, Tramontano D, Fusco A: HMGA1 and HMGA2 protein expression in mouse spermatogenesis. Oncogene 2002, 21:3644-3650.

18. Brero A, Easwaran HP, Nowak D, Grunewald I, Cremer T, Leonhardt H, Cardoso MC: Methyl CpG-binding proteins induce large-scale chromatin reorganization during terminal differentiation. J Cell Biol 2005, 169:733-743.

19. Muráni E, Murániová M, Ponsuksili S, Schellander K, Wimmers K: Identification of genes differentially expressed during prenatal development of skeletal muscle in two pig breeds differing in muscularity. BMC Dev Biol 2007, 7:109.

20. Battista S, Pentimalli F, Baldassarre G, Fedele M, Fidanza V, Croce CM, Fusco A: Loss of Hmga1 gene function affects embryonic stem cell lympho-hematopoietic differentiation. FASEB J 2003, 17:1496-1498.

21. Liu J, Schiltz JF, Ashar HR, Chada KK: Hmga1 is required for normal sperm development. Mol Reprod Dev 2003, 66:81-89.

22. Melillo RM, Pierantoni GM, Scala S, Battista S, Fedele M, Stella A, De Biasio MC, Chiappetta G, Fidanza V, Condorelli G, Santoro M, Croce CM, Viglietto G, Fusco A: Critical role of the HMGI(Y) proteins in adipocytic cell growth and differentiation. Mol Cell Biol 2001, 21:2485-2495.

23. Agalioti T, Lomvardas S, Parekh B, Yie J, Maniatis T, Thanos D: Ordered recruitment of chromatin modifying and general transcription factors to the IFN-beta promoter. Cell 2000, 103:667-678.

24. Merika M, Thanos D: Enhanceosomes. Curr Opin Genet Dev 2001, 11:205-208.

25. Palacios D, Summerbell D, Rigby PWJ, Boyes J: Interplay between DNA Methylation and Transcription Factor Availability: Implications for Developmental Activation of the Mouse Myogenin Gene. Mol Cell Biol 2010, 30:3805-15.

26. Bilan PJ, Ramlal T, Klip A: IGF-I mediated recruitment of glucose transporters from intracellular membranes to plasma membranes in L6 muscle cells. Adv Exp Med Biol 1991, 293:273-288.

27. Adi S, Cheng ZQ, Zhang PL, Wu NY, Mellon SH, Rosenthal SM: Opposing early inhibitory and late stimulatory effects of insulin-like growth factor-I on myogenin gene transcription. J Cell Biochem 2000, 78:617-626.

28. Cheng CM, Reinhardt RR, Lee WH, Joncas G, Patel SC, Bondy CA: Insulinlike growth factor 1 regulates developing brain glucose metabolism. Proc Natl Acad Sci USA 2000, 97:10236-10241.

29. Florini JR, Ewton DZ, Magri KA: Hormones, growth factors, and myogenic differentiation. Annu Rev Physiol 1991, 53:201-216.

30. Florini JR, Ewton DZ, Coolican SA: Growth hormone and the insulin-like growth factor system in myogenesis. Endocr Rev 1996, 17:481-517.

31. Hasty P, Bradley A, Morris JH, Edmondson DG, Venuti JM, Olson EN, Klein WH: Muscle deficiency and neonatal death in mice with a targeted mutation in the myogenin gene. Nature 1993, 364:501-506.

32. Nabeshima Y, Hanaoka K, Hayasaka M, Esumi E, Li S, Nonaka I, Nabeshima Y: Myogenin gene disruption results in perinatal lethality because of severe muscle defect. Nature 1993, 364:532-535.

33. Tsuchiya K, Hosoi H, Misawa-Furihata A, Houghton PJ, Sugimoto T: Insulinlike growth factor-I has different effects on myogenin induction and cell cycle progression in human alveolar and embryonal rhabdomyosarcoma cells. Int J Oncol 2007, 31:41-47.

34. Montarras D, Aurade F, Johnson T, llan J, Gros F, Pinset C: Autonomous differentiation in the mouse myogenic cell line, $C_{2}$, involves a mutual positive control between insulin-like growth factor II and MyoD, operating as early as at the myoblast stage. J Cell Sci 1996, 109(Pt 3):551-560.

35. Narita M, Narita M, Krizhanovsky V, Nuñez S, Chicas A, Hearn SA, Myers MP, Lowe SW: A novel role for high-mobility group a proteins in cellular senescence and heterochromatin formation. Cell 2006, 126:503-514.

36. Zhao K, Käs E, Gonzalez E, Laemmli UK: SAR-dependent mobilization of histone $\mathrm{H} 1$ by $\mathrm{HMG}-\mathrm{I} / \mathrm{Y}$ in vitro: HMG-I/Y is enriched in $\mathrm{H} 1$-depleted chromatin. EMBO J 1993, 12:3237-3247.

37. Catez F, Brown DT, Misteli T, Bustin M: Competition between histone H1 and HMGN proteins for chromatin binding sites. EMBO Rep 2002, 3:760-766

38. Nightingale K, Dimitrov S, Reeves R, Wolffe AP: Evidence for a shared structural role for HMG1 and linker histones B4 and H1 in organizing chromatin. EMBO J 1996, 15:548-561.

39. Agarwal N, Hardt T, Brero A, Nowak D, Rothbauer U, Becker A, Leonhardt $H$, Cardoso MC: MeCP2 interacts with HP1 and modulates its heterochromatin association during myogenic differentiation. Nucleic Acids Res 2007, 35:5402-5408.

40. Soneoka Y, Cannon PM, Ramsdale EE, Griffiths JC, Romano G, Kingsman SM, Kingsman AJ: A transient three-plasmid expression system for the production of high titer retroviral vectors. Nucleic Acids Res 1995, 23:628-633.

41. Hock R, Scheer U, Bustin M: Chromosomal proteins HMG-14 and HMG-17 are released from mitotic chromosomes and imported into the nucleus by active transport. J Cell Biol 1998, 143:1427-1436.

42. Yamagishi $Y$, Sakuno $T$, Shimura M, Watanabe $Y$ : Heterochromatin links to centromeric protection by recruiting shugoshin. Nature 2008, 455:251-255.

43. Bustin M: Preparation and application of immunological probes for nucleosomes. Meth Enzymol 1989, 170:214-251.

\section{doi:10.1186/1471-2121-11-64}

Cite this article as: Brocher et al:: HMGA1 down-regulation is crucial for chromatin composition and a gene expression profile permitting myogenic differentiation. BMC Cell Biology 2010 11:64.

\section{Submit your next manuscript to BioMed Central and take full advantage of:}

- Convenient online submission

- Thorough peer review

- No space constraints or color figure charges

- Immediate publication on acceptance

- Inclusion in PubMed, CAS, Scopus and Google Scholar

- Research which is freely available for redistribution
Ciomed Central 